\title{
Arterial Stiffness and its Association with Dyslipidemia
}

\author{
Razman $M R^{a}$, Jamaluddin $A R^{a}$, Ellyda $M N^{b}$, Seikh $F A^{a}$ \\ a Department of Community Medicine, Kulliyyah of Medicine, International Islamic University Malaysia, \\ Kuantan, Pahang, Malaysia \\ ${ }^{b}$ Department of Radiology, Kulliyyah of Medicine, International Islamic University Malaysia, Kuantan, Pahang, \\ Malaysia
}

\begin{abstract}
Introduction: Cardiovascular diseases (CVD) are the leading cause of mortality in Malaysia as well as in other countries. It is associated with many risk factors, such as increasing age, hypertension, diabetes, dyslipidemia, oxidative stress and autonomic dysfunction and arterial stiffness. The objectives of this study were to measure the prevalence of arterial stiffness and to assess its association with dyslipidemia. Methods: A cross sectional study was conducted in a rural community in Malaysia involving 146 subjects. Data were collected using an interviewer administered questionnaire which included three sections - sociodemographic characteristics, personal profile, and past medical history. In addition, Seca Body Meter (Seca 220) was used to measure height and weight. Sphygmomanometer (OMRON Automatic Blood Pressure Monitor HEM 907) and SphygmoCor-AtCor MM3 SERIAL/RS-232 were used for blood pressure and augmentation index (Alx) measurement. Data were analysed using the SPSS for Windows, Version 18.0. Results: The mean age of respondents was 49.5 years, $\mathrm{SD} \pm$ 15.6. The prevalence of arterial stiffness was 23.3\% (95\% Confidence Interval $(\mathrm{Cl}): 16.44-30.16)$. The prevalence of dyslipidemia was $82.9 \%$ (95\% Cl: $76.79-89.01)$. Multivariate logistic regression revealed that total cholesterol was significantly associated with arterial stiffness $(\mathrm{OR}=4.56, \mathrm{Cl} 1.10-18.90)$. Conclusion: The prevalence of dyslipidemia was high. Despite an insignificant association between dyslipidemia and Alx, there is a significant association between TC level and Alx.
\end{abstract}

KEYWORDS: Arterial stiffness, dyslipidemia, Augmentation Index, total cholesterol

\section{INTRODUCTION}

Over the last four decades, cardiovascular disease (CVD) has been the leading cause of death in Malaysia as well as in many countries. ${ }^{1,2}$ Many factors can cause CVD and arterial stiffness is one of them. ${ }^{2}$

Arterial stiffness is a generic term for arterial compliance, distensibility and elasticity. ${ }^{3}$ Increased arterial stiffness is proposed as a possible mechanism in the initiation and/or progression of atherosclerosis and hypertension. Dyslipidemia is associated with a number of cardiovascular risk factors, which was supported by a study done in 2006 by The National Cardiovascular Disease Database in which the prevalence of dyslipidemia among CVD patients was 55.9\%. ${ }^{4}$ The Malaysia National Health and Morbidity Survey III 2006 (NHMS, 2006) found that the prevalence

Corresponding author:

Dr Razman Mohd Rus

Department of Community Medicine,

Kulliyyah of Medicine,

International Islamic University Malaysia,

25200 Kuantan,

Pahang, Malaysia

Tel:+60169890228

Fax: +6095716798

Email: razman@iium.edu.my

of dyslipidemia was $20.7 \%$. Dyslipidemia is defined as a condition whereby lipid values of a person fall outside the norm as according to Malaysia Clinical Practice Guidelines (CPG) on Management of Dyslipidemia (4th edition).

Several parameters can provide information on arterial stiffness. Among all these techniques are Alx, augmentation pressure (AP), pressure pulse waveforms (PPW), ejection duration and subendocardial viability ratio (SEVR). ${ }^{5}$ In this study; the Alx was used as a parameter to measure arterial stiffness because previously, there was a study that showed a positive correlation between Alx and cholesterol levels. ${ }^{6,7}$ Therefore, this study focused to measure the prevalence of arterial stiffness and its association with dyslipidemia. Table I briefly summarizes the various studies conducted on the association between arterial stiffness and lipid parameters. 
Table I. Summary statement of various studies on the association between arterial stiffness and the various lipid parameters

\begin{tabular}{|c|c|c|c|c|}
\hline \multirow[t]{2}{*}{ Lipid parameter } & \multicolumn{2}{|c|}{ Studies showed association } & \multicolumn{2}{|l|}{ Disproving association } \\
\hline & Study & Method & Study & Method \\
\hline \multirow[t]{2}{*}{ HDL } & Miao, Ye et al. 2011 & $\begin{array}{l}\text { LV Diastolic } \\
\text { Function Index } \\
\text { (E/Em) }\end{array}$ & $\begin{array}{l}\text { Wilkinson et al., } \\
2002\end{array}$ & $\begin{array}{l}\text { Alx and Aortic } \\
\text { PWV }\end{array}$ \\
\hline & $\begin{array}{l}\text { Sutton-Tyrrell, } \\
\text { et al., } 2001\end{array}$ & Aortic PWV & & \\
\hline LDL & Brinkley et al., 2009 & Aortic PWV & Miao, Ye et al. 2011 & $\begin{array}{l}\text { LV Diastolic } \\
\text { Function Index } \\
\text { (E/Em) }\end{array}$ \\
\hline TG & $\begin{array}{l}\text { Legedz, Bricca et al. } \\
2006 \\
\text { Sutton-Tyrrell, et } \\
\text { al., } 2001\end{array}$ & $\begin{array}{l}\text { Aortic PWV } \\
\text { Aortic PWV }\end{array}$ & $\begin{array}{l}\text { Wilkinson et al., } \\
2002\end{array}$ & $\begin{array}{l}\text { Alx, Aortic } \\
\text { PWV }\end{array}$ \\
\hline $\mathrm{TC}$ & $\begin{array}{l}\text { Wilkinson et al., } \\
2002 \\
\text { Pirro et al., } 2004\end{array}$ & $\begin{array}{l}\text { Alx and Aortic } \\
\text { PWV } \\
\text { Aortic PWV }\end{array}$ & $\begin{array}{l}\text { Miao, Ye et al } \\
2011\end{array}$ & $\begin{array}{l}\text { LV Diastolic } \\
\text { Function } \\
\text { Index }(\mathrm{E} / \mathrm{Em})\end{array}$ \\
\hline
\end{tabular}

PWV: pulse wave velocity, Aix: Augmentation Index, LV: left ventricular.

\section{METHODOLOGY}

A cross-sectional study was carried out among adults in a rural community (Kampung Alor Batu in Kuantan, Pahang, Malaysia) from $17^{\text {th }}$ February 2012 to $4^{\text {th }}$ March 2012. Adults were defined as residents aged 18 years and above. There were 1260 inhabitants in 200 houses. Single proportion formula was used to determine the sample size. By using $\mathrm{P}$ as 0.207 based on the prevalence of dyslipidemia in NHMS III 2006 and detectable difference of 0.05 , the minimum required sample is 252 samples. Another $20 \%$ was added considering the non-respondent, making the final required sample size of 300 samples. However, it was possible to obtain 146 samples within the stipulated time-frame as mentioned earlier.

All adults fulfilled the criteria of being a Malaysian and current resident of the studied community. Interviewer -based questionnaire was conducted. Adults who refused to participate; not available at home after three visits; failed to present themselves during blood taking, SphygmoCor and anthropometric measurement day; and pregnant women were dropped from this study (refer Figure 1). Out of the 158 respondents, 12 of them were further excluded from the data analysis due to incomplete data in which there were nine respondents with operator index $<80 \%$, one respondent with ectopic beats (not applicable), one respondent with Alx that was unable to be calculated and one respondent with too high TG (LDL was not able to be calculated). Thus, final total sample of this study was 146.
A validated questionnaire was administered to the participants. The three sections of the questionnaire were sociodemographic history, personal history, and past medical history. Measurements taken for the study were anthropometry, blood pressure, BMI and Alx. Alx was measured using Sphygmocor-AtCor MM3 SERIAL/ RS-232 and was defined as the difference of the first systolic and second pressure peak, expressed as a percentage of the pulse pressure. The numerical values of Alx indicate estimation of arterial stiffness, correlating with the increase in aortic pressure. According to SphygmoCor interpretations, normal Alx is when the value is not within the upper $5 \%$ of the confidence interval $(\mathrm{Cl})$ while abnormal Alx is when the value is within the upper $5 \%$ of $\mathrm{Cl}^{8}$ Only two team members became operators of the device, and an operator index of $80 \%$ was set as the lowest limit in order to obtain valid results.

Dyslipidemia was defined based on CPG, Management of Dyslipidemia 2011, (4 ${ }^{\text {th }}$ Edition) by analyzing the fasting blood lipid profile. Respondents were instructed to fast starting at least 6 hours prior to blood taking. Blood was withdrawn from the brachial vein at antecubital fossa and transferred to appropriate tube before being analyzed. Other measuring tools used were OMRON Automatic Blood Pressure Monitor HEM 907 for blood pressure measurement; and Seca Height and Weighting Scales (Seca model 220) respectively for height and weight measurement. Training was conducted among the researcher of this study to 
standardize the measurement according to the Centre for Disease Control (CDC) National Health and Nutrition Examination Survey (NANES 2004) to reduced inter-operator and intra-operator variability. Days prior to data collection and under the supervision of a medical assistant, students were trained to appropriately use measuring tools, especially SphygmoCor, until constant and reliable values were achieved for each measurement. All measurements were taken during the five data collection sessions which took place throughout five days of three consecutive weekends.

Figure 1. Flowchart

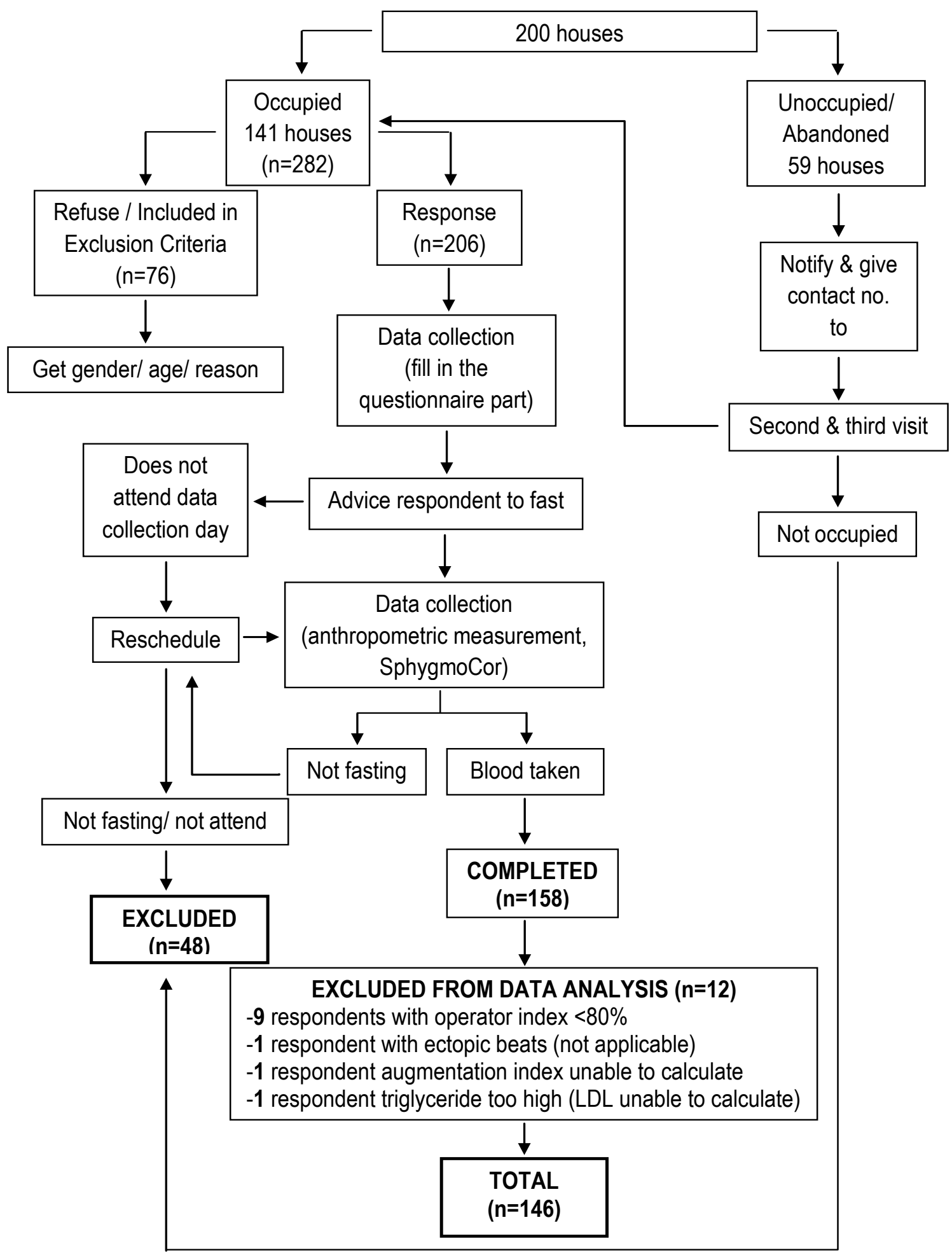




\section{Statistical Analysis}

The data were analyzed by using SPSS software (PASW 18.0) for Windows. The descriptive statistics were described as mean and standard deviation (SD) or median and inter quartile range (IQR) for numerical variables. Numbers and percentage (\%) were used for categorical variables. Chi-square analysis and independent sample $t$ test were used to measure that association between arterial stiffness, and its risk factors namely age, gender, education level, BMI group, smoking, hypertension, diabetes mellitus and dyslipidemia. Logistic regression was performed to compute odds ratio (OR) and $95 \% \mathrm{Cl}$ for relationships between arterial stiffness, and its risk factors specifically dyslipidemia. All associations were first analyzed without adjustments and then with adjustment for potential confounder, which comprise of age, gender, smoking, BMI group, hypertension, and diabetes mellitus. The adjusted OR was estimated with $95 \% \mathrm{Cl}$.

\section{RESULTS}

Table II shows the socio demographic characteristics and potential risk factors of arterial stiffness. The study population consisted of 146 respondents with mean age of $49.6(15.60)$ years; $64.4 \%$ (94) were females; $32.2 \%$ (47) completed secondary level; $29.5 \%$ (43) were overweight and $39.7 \%$ (58) were obese. Meanwhile, $25.3 \%$ (37) were smokers; $25.3 \%$ (37) were hypertensives, $11.0 \%$ (16) were diabetics and $82.9 \%$ (121) $(95 \% \mathrm{Cl} 76.92,89.08)$ were dyslipidemia respondents.

Table II. Sociodemographic characteristics, status of arterial stiffness with potential risk factor

\begin{tabular}{|c|c|c|c|c|}
\hline & \multirow{3}{*}{$\begin{array}{l}\text { Total Respondents } \\
(\mathrm{N}=146)\end{array}$} & \multicolumn{2}{|l|}{ Arterial Stiffness ${ }^{a}$} & \multirow[t]{3}{*}{$\mathrm{P}$ value } \\
\hline & & Yes & No & \\
\hline & & $(\mathrm{N}=34)$ & $(\mathrm{N}=112)$ & \\
\hline Age (year) & $49.60(15.60)^{c}$ & $37.03(13.21)^{c}$ & $53.42(14.25)^{c}$ & $<0.001$ \\
\hline Monthly Household & $895(1125)^{d}$ & $1016.67(1313)^{d}$ & $807.50(1000)^{d}$ & 0.15 \\
\hline \multicolumn{5}{|l|}{ Income (RM) } \\
\hline \multicolumn{5}{|l|}{ Gender (\%) } \\
\hline Male & $52(35.6)$ & $10(19.2)$ & $42(80.8)$ & 0.39 \\
\hline Female & $94(64.4)$ & $24(25.5)$ & $70(74.5)$ & \\
\hline \multicolumn{5}{|l|}{ Education (\%) } \\
\hline No Formal Education & $16(11.0)$ & $3(18.8)$ & 13. (81.3) & 0.03 \\
\hline Not Completed Primary & $30(20.5)$ & $2(6.7)$ & $28(93.3)$ & \\
\hline Completed Primary & $47(32.2)$ & $10(21.3)$ & 37 (78.7) & \\
\hline Completed Secondary & $47(32.2)$ & $17(36.2)$ & $30(63.8)$ & \\
\hline Completed Tertiary & $6(4.1)$ & $2(33.3)$ & $4(66.7)$ & \\
\hline \multicolumn{5}{|l|}{ Smoking (\%) } \\
\hline Yes & $37(25.3)$ & $6(16.2)$ & $31(83.8)$ & 0.24 \\
\hline No & $109(74.7)$ & $28(25.7)$ & $81(74.3)$ & \\
\hline \multicolumn{5}{|l|}{ BMI (\%) } \\
\hline Underweight & $14(9.6)$ & $4(28.6)$ & $10(71.4)$ & 0.33 \\
\hline Normal & $31(21.2)$ & $4(12.9)$ & $27(87.1)$ & \\
\hline Overweight & $43(29.5)$ & $13(30.2)$ & $30(69.8)$ & \\
\hline Obese & $58(39.7)$ & $13(22.4)$ & $45(77.6)$ & \\
\hline \multicolumn{5}{|l|}{ Hypertension (\%) } \\
\hline Yes & $37(25.3)$ & $3(8.1)$ & 34 (91.9) & 0.01 \\
\hline No & $109(74.7)$ & $31(28.4)$ & 78 (71.6) & \\
\hline \multicolumn{5}{|l|}{ Diabetes Mellitus (\%) } \\
\hline Yes & $16(11.0)$ & $1(6.3)$ & $15(93.8)$ & 0.12 \\
\hline No & $130(89.0)$ & $33(25.4)$ & $97(74.6)$ & \\
\hline \multicolumn{5}{|l|}{ Dyslipidemia (\%) } \\
\hline Yes & $121(82.9)$ & $26(21.5)$ & $95(78.5)$ & 0.26 \\
\hline No & $25(17.1)$ & $8(32.0)$ & $17(68.0)$ & \\
\hline
\end{tabular}

a Arterial stiffness is defined as Augmentation Index (Alx) of upper $5 \%$ of reference range as determined by SphygmoCor;

${ }^{\mathrm{b}}$ All $\mathrm{P}$ values are determined by $\mathrm{X}^{2}$ test except for age and income (independent sample $t$ test)

cMean (SD), ${ }^{\mathrm{d}}$ Median (IQR). 
The prevalence of arterial stiffness was $23.3 \%$ (34) $(95 \% \mathrm{Cl} 16.14,29.86)$ in this study population. Among the arterial stiffness group, the mean age was of $37(13.21)$ years; $70.5 \%$ (24) were females; $50 \%$ (17) completed secondary level; $38.3 \%$ (13) were overweight and obese; $17.6 \%$ (6) were smokers; $8.8 \%$ (3) were hypertensives and $2.9 \%$ (1) were diabetics.

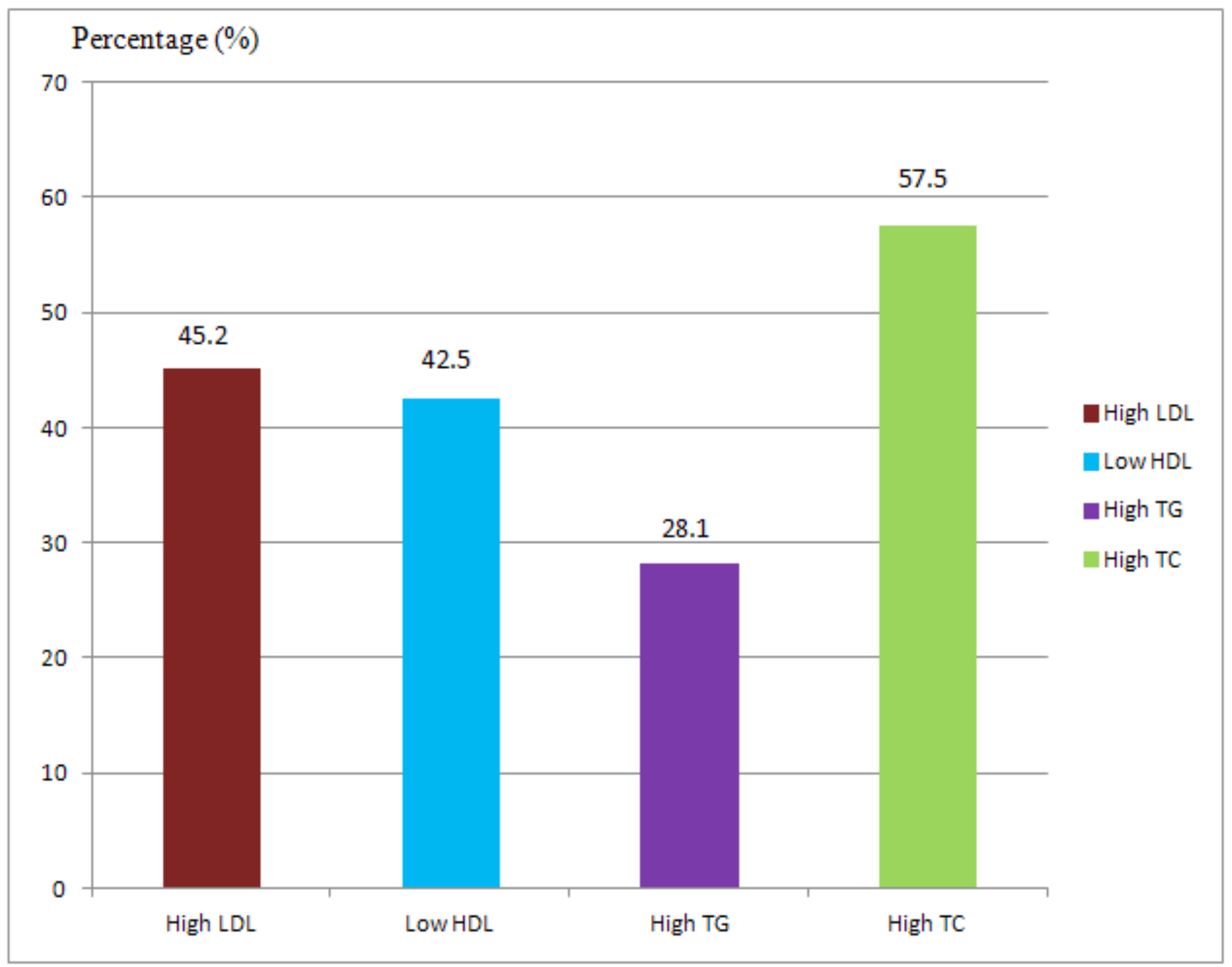

Figure 2. Distribution of different types of dyslipidemia

Figure 2 summarizes the distribution of different types of dyslipidemia. Among 146 respondents, it was found that $45.2 \%$ (66) had high LDL, 42.5\% (62) had low HDL, $28.1 \%$ (41) had high TG and $57.5 \%$ (84) had high TC. Table III shows the association of arterial stiffness with age, gender, smoking habit, BMI group, diabetes mellitus, hypertension and dyslipidemia. In a simple model unadjusted for arterial stiffness risk factor, the OR for arterial stiffness of increasing age was 0.92 $(95 \% \mathrm{Cl} 0.89,0.95)$; male was 0.69 ( $95 \% \mathrm{Cl} 0.30,1.59)$; smoker was $0.56(95 \% \mathrm{Cl} 0.21,1.48)$; diabetes was
$0.20(95 \% \mathrm{Cl} 0.03,1.54)$; hypertension was $0.22(95 \%$ $\mathrm{Cl} 0.06,0.78)$; and dyslipidemia was $1.72(95 \% \mathrm{Cl} 0.67$, 4.43). In bivariate analysis and adjusted for arterial stiffness risk factors, only increasing age which had OR of $0.92(95 \% \mathrm{Cl} 0.88,0.96)$ was associated with a decreased risk of arterial stiffness. The OR for both unadjusted and adjusted indicated that the elderly groups of respondents have a lower risk of getting arterial stiffness than younger respondents. 
Table III. Association of arterial stiffness with age, gender, smoking habit, BMI group, diabetes mellitus, hypertension and dyslipidemia

\begin{tabular}{|c|c|c|c|c|}
\hline & \multicolumn{2}{|c|}{ Unadjusted } & \multicolumn{2}{|c|}{ Adjusted $^{\mathrm{a}}$} \\
\hline & OR & $95 \% \mathrm{Cl}$ & OR & $95 \% \mathrm{Cl}$ \\
\hline \multicolumn{4}{|l|}{ Gender } & $0.88-0.96$ \\
\hline Male & 0.69 & $0.30-1.59$ & 0.51 & $0.14-1.88$ \\
\hline Female & 1.00 & & 1.00 & \\
\hline \multicolumn{5}{|l|}{ Smoking } \\
\hline Yes & 0.56 & $0.21-1.48$ & 2.28 & $0.46-11.19$ \\
\hline No & 1.00 & & 1.00 & \\
\hline \multicolumn{5}{|l|}{ BMI Group } \\
\hline Normal & 1.00 & & 1.00 & \\
\hline Underweight & 2.70 & $0.57-12.91$ & 1.93 & $0.30-12.46$ \\
\hline Overweight & 2.93 & $0.85-10.06$ & 3.21 & $0.75-13.76$ \\
\hline Obese & 1.95 & $0.58-6.60$ & 1.58 & $0.38-6.53$ \\
\hline \multicolumn{5}{|l|}{ Diabetes Mellitus } \\
\hline Yes & 0.20 & $0.03-1.54$ & 0.67 & $0.07-6.12$ \\
\hline No & 1.00 & & 1.00 & \\
\hline \multicolumn{5}{|l|}{ Hypertension } \\
\hline Yes & 0.22 & $0.06-0.78$ & 0.72 & $0.17-3.06$ \\
\hline No & 1.00 & & 1.00 & \\
\hline \multicolumn{5}{|l|}{ Dyslipidemia } \\
\hline Yes & 1.72 & $0.67-4.43$ & 0.84 & $0.25-2.83$ \\
\hline No & 1.00 & & 1.00 & \\
\hline
\end{tabular}

${ }^{a}$ Adjusted for age, gender, smoking, BMI group, diabetes mellitus, hypertension and dyslipidemia

We had found in this study that arterial stiffness was hot significantly associated with dyslipidemia with adjusted OR of $0.84(95 \% \mathrm{Cl} 0.25,2.83)$. However, when we further analyzed the result, we found that only high TC was significantly associated with arteria stiffness with adjusted OR of $4.56(95 \% \mathrm{Cl} 1.10,18.90)$ as in Table IV.

Table IV. $\quad$ Association of arterial stiffness with status of lipoproteins

\begin{tabular}{llll} 
Unadjusted & \multicolumn{3}{c}{ Adjusted $^{\mathrm{a}}$} \\
\hline OR & $95 \% \mathrm{Cl}$ & OR & $95 \% \mathrm{Cl}$ \\
\hline
\end{tabular}

Low Density Lipoprotein

$\begin{array}{lllll}\text { High } & 0.69 & 0.31-1.51 & 1.87 & 0.49-7.22 \\ \text { Normal } & 1.00 & & 1.00 & \end{array}$

High Density Lipoprotein

$\begin{array}{lllll}\text { Low } & 0.93 & 0.43-2.03 & 0.85 & 0.31-2.37 \\ \text { Normal } & 1.00 & & 1.00 & \end{array}$

Triglycerides

$\begin{array}{lllll}\text { High } & 0.47 & 0.18-1.24 & 0.38 & 0.10-1.45 \\ \text { Normal } & 1.00 & & 1.00 & \end{array}$

Total Cholesterol

$\begin{array}{lllll}\text { High } & 1.07 & 0.49-2.33 & 4.56 & 1.10-18.90 \\ \text { Normal } & 1.00 & & 1.00 & \end{array}$

${ }^{\text {a }}$ Adjusted for age, gender, smoking, BMI group, diabetes mellitus and hypertension 


\section{DISCUSSION}

In this study, prevalence of dyslipidemia was $82.9 \%$ (95\% $\mathrm{Cl} 77.4,88.4)$. This was very much different from NHMS 2006, which stated that the prevalence of dyslipidemia in Malaysia was $20.6 \%(95 \% \mathrm{Cl} 20.1,21.3)$. However, the difference in the prevalence of dyslipidemia found was probably due to the difference in definition used by NHMS 2006, in which only TC was taken into account.

One of the main objectives of this study was to find the association of dyslipidemia and arterial stiffness. We found that dyslipidemia after adjusting for all other confounders to be not significantly associated with arterial stiffness (adjusted OR 0.84, 95\% Cl 0.25, 2.83). After analyzing the different types of dyslipidemia, even after adjusting for other confounders, we found that TC was significantly associated with arterial stiffness as the odds ratio was $4.56(95 \% \mathrm{Cl} 1.10$, 18.90). This result was also demonstrated in another research perform in the United Kingdom. ${ }^{7}$ We found that high LDL, low HDL and high TG levels were not associated with arterial stiffness as it was statistically not significant. This result was in line with a study in China, which stated that LDL and HDL were not associated with arterial stiffness and another research in France, which said that there was a negative relationship between HDL and arterial stiffness. ${ }^{9,10}$

The prevalence of arterial stiffness in this study was $23.3 \%(95 \% \mathrm{Cl} 17.1,29.5)$. From that, we found that the majority of respondents with arterial stiffness were females; which is $70.6 \%(95 \% \mathrm{Cl} 63.9,77.3)$. After adjusting for other confounders, the association of gender with arterial stiffness in this study was found to be statistically not significant (adjusted OR 0.51, $95 \% \mathrm{Cl} 0.14,1.88$ ). This finding was not in line with another study, which stated that more adult males would develop stiffer large vessels. ${ }^{11}$ Another study in Florida also showed that males were more likely to get arterial stiffness. ${ }^{12}$

In terms of age, this study showed an inverse relation between increasing age and arterial stiffness. In fact, after adjusting for other confounders it was statistically significant (adjusted OR 0.92, 95\% Cl $0.88,0.96)$. A different study done stated that arterial stiffness could be as a result of ageing, which differ from this study..$^{13}$ However, there was a study which found that non invasive measurement of arterial stiffness such as SphygmoCor was unreliable for healthy young adults, which may have caused some of the over estimation of arterial stiffness in young individuals. ${ }^{14}$

In an Irish study, current and ex-smokers had significantly higher pulse wave velocity and Alx compared with non-smokers..$^{15}$ As for this study, even after adjusting for other risk factors, current and ex-smokers have statistically no significant association to arterial stiffness (adjusted OR 2.28, 95\% Cl 0.46, 11.19). Although statistically not significant, the odds ratio of diabetes mellitus (adjusted OR $0.67,95 \% \mathrm{Cl}$ $0.07,6.12$ ) and hypertension (adjusted $0.72,95 \% \mathrm{Cl}$
$0.17,3.06$ ) were found to be much lower as compared to non diabetic patients and non hypertensive patients respectively. These results did not go with other studies, which stated that diabetes mellitus and hypertension were positively associated with increased arterial stiffness. ${ }^{16,17}$

This study also did not show any association between obesity and arterial stiffness as it was statistically not significant even after adjusting for other confounders (adjusted OR 1.58, 95\% Cl 0.38, 6.53). Nonetheless, this finding was different to a study done in France, which revealed that obese subjects were more likely to have arterial stiffness. ${ }^{18}$

In terms of limitations, debates on the reliability of SphygmoCor have long been ongoing. A study by Hope et al., reported that there was no correlation between measured Alx and that estimated from a transfer function (TF) and thus of no additional clinical benefit. ${ }^{19}$ The main disadvantage of using the radial pulse is that the use of TF might inevitably result in some errors in estimating the true Alx. ${ }^{20}$ This is due to pressure contour changes appreciably as it travels from the aorta to more peripheral sites. ${ }^{21}$ The categorization of Alx into two major group namely normal or stiff arterial group decreased the power of the data. The Alx normal range is based on a research conducted in Cardiff UK. However, there has been no local research done to analyze the compatibility of this range in this region.

The findings from this study urged us to take serious actions. High prevalence of dyslipidemia and obese people indicate lack of health awareness among the population. Even more surprisingly, dyslipidemia is not only common among the elderly, but also a common scenario among the younger age group as supported by a study done in Mumbai. This study revealed a high prevalence of dyslipidemia among young males which increase their risk of developing Coronary Artery Disease (CAD) that may lead to premature cardiovascular infarction. ${ }^{22}$ Thus, screening of dyslipidemia should be encouraged at an earlier age. Health promotion programmes such as dietary modification, smoking-cessation programme and physical exercise should be conducted in a fresher and creative approach.

\section{CONCLUSION}

The researchers attempted to find the association between dyslipidemia and arterial stiffness as there is known correlation between these two. Using a cross-sectional study with 146 samples, the researchers found a high prevalence of dyslipidemia; however, the researchers did not find any significant association between dyslipidemia and Alx. Despite an insignificant association between dyslipidemia and Alx, there is a significant association between TC level and Alx. We however, found a statistically significant inverse relation between increasing age and arterial stiffness. 


\section{ACKNOWLEDGEMENT}

The authors would like to express the highest appreciation to the Dean of Kulliyyah of Medicine, IIUM. We would also like to thank the medical undergraduate students for their sincere contribution in data collection and the inhabitants of Kampung Alor Batu, Kuantan for their participation.

\section{REFERENCES}

1. Rampal L, Rampal S, Azhar M, Rahman A. Prevalence, awareness, treatment and control of hypertension in Malaysia: A national study of 16,440 subjects. Public Health 2008; 122:11-8.

2. Mattace-Raso FUS, van der Cammen TJM, Hofman A, et al. Arterial stiffness and risk of coronary heart disease and stroke. Circulation 2006; 113:657-63.

3. Woodman RJ, Watts GF. Measurement and application of arterial stiffness in clinical research: focus on new methodologies and diabetes mellitus. Med Sci Monit 2003; 9:81-9.

4. Ahmad WAW, Hian SK. Report of the Acute Coronary Syndrome (ACS) Registry. National Cardiovascular Disease Database (NCVD) 2006: 60-85.

5. Skinner SL, Barin E, Gallery ED, et al. Clinical Guide Pulse Wave Analysis. At The Heart of Cardiovascular Management. 2001:1-4. [unpublished]

6. Nürnberger J, Keflioglu-Scheiber A, Opazo Saez $\mathrm{AM}$, et al. Augmentation index is associated with cardiovascular risk. J Hypertens 2002; 20:2407.

7. Mackenzie IS, Wilkinson IB, Cockcroft JR. Assessment of arterial stiffness in clinical practice. QJM 2002; 95:67-74.

8. Murgo JP, Westerhof N, Giolma JP, Altobelli S. Aortic input impedance in normal man: relationship to pressure wave forms. Circulation 1980; 62:105-16.

9. Miao DM, Ye P, Xiao WK, et al. Influence of low high-density lipoprotein cholesterol on arterial stiffening and left ventricular diastolic dysfunction in essential hypertension. J Clin Hypertens 2011; 13:710-5.

10. Asmar R, Benetos A, London G, et al. Aortic distensibility in normotensive, untreated and treated hypertensive patients. Blood Press 1995; 4:48-54.

11. Ahimastos AA, Formosa M, Dart AM, Kingwell BA. Gender differences in large artery stiffness pre-and post puberty. J Clin Endocrinol Metab 2003; 88:5375.

12. Hlaing W, Koutoubi S, Huffman FG. Differences in arterial stiffness and its correlates in tri-ethnic young men and women. Ethn Dis 2006; 16:837-43.

13. Cockcroft JR, Wilkinson IB, Webb DJ. The Trevor Howell Lecture. Age, arterial stiffness and the endothelium. Age Ageing 1997; 26:53-60.
14. Huck CJ, Bronas UG, Williamson EB, et al. Noninvasive measurements of arterial stiffness: Repeatability and interrelationships with endothelial function and arterial morphology measures. Vasc Health Risk Manag 2007; 3:343-9.

15. Jatoi NA, Jerrard-Dunne P, Feely J, Mahmud A. Impact of smoking and smoking cessation on arterial stiffness and aortic wave reflection in hypertension. Hypertension 2007;49:981-5.

16. Schram MT, Henry R, van Dijk RAJM, et al. Increased central artery stiffness in impaired glucose metabolism and type 2 diabetes. Hypertension 2004; 43:176-81.

17. Arnett DK, Evans GW, Riley WA. Arterial stiffness: a new cardiovascular risk factor? Am J Epidemiol 1994; 140:669-82.

18. Safar ME, Czernichow S, Blacher J. Obesity, arterial stiffness, and cardiovascular risk. J Am Soc Nephrol 2006; 17:S109-11.

19. Hope SA, Tay DB, Meredith IT, Cameron JD. Use of arterial transfer functions for the derivation of aortic waveform characteristics. J Hypertens 2003; 21:1299-305.

20. Lin MM, Cheng HM, Sung SH, et al. Estimation of central aortic systolic pressure from the second systolic peak of the peripheral upper limb pulse depends on central aortic pressure waveform morphology. J Hypertens 2012; 30:581-6.

21. Pauca A, Wallenhaupt S, Kon N, Tucker W. Does radial artery pressure accurately reflect aortic pressure? Chest 1992; 102:1193-8.

22. Sawant A, Shetty D, Mankeshwar R, Ashavaid TF. Prevalence of dyslipidemia in young adult Indian population. J Assoc Physicians India 2008; 56:99-102. 